\title{
Mechanisms of the bronchoconstrictor effects of deep inspiration in asthmatic patients ${ }^{*}$
}

\author{
P GAYRARD, ${ }^{1}$ J OREHEK, ${ }^{2}$ CH GRIMAUD, ${ }^{2}$ AND J CHARPIN ${ }^{1}$
}

From the clinique de Pneumo-Phtisiologie et Allergologie, Hôpital Sainte Marguerite, ${ }^{1}$ and the Laboratoire de Médecine Expérimentale, Faculté de Médecine de Marseille, ${ }^{2}$ Marseille, France

ABSTRACT A single deep inspiration (DI) is commonly followed by transient airflow obstruction in asthmatic patients. In some patients, however, DI results in a sustained response which suggests that more than one mechanism may be responsible. We have studied the characteristics of the response to repeated DI, and their modification by various pharmacological agents, by measuring specific airway resistance (sRaw) in ten subjects who showed reproducible and consistent increases in sRaw after DI. Two types of reaction were observed: type $A(n=8)$ had an immediate maximum and usually short persistence; type $B(n=2)$ had a delayed maximum with a progressive increase. In type A reactions repetition of DI showed different patterns of response-either a reproducible reaction to each DI or a plateau effect. In type B reactions the response spontaneously increased with repeated DI.

Type A responses to DI were inhibited completely by a beta-adrenergic stimulant (BAS), largely by an anticholinergic drug (AC, ipratropium bromide), but in no case by disodium cromoglycate (DSCG). Type B responses were inhibited completely by BAS, largely by DSCG, and partially by AC. These findings suggest that the response to DI is due to bronchoconstriction, which in type A reactions is of reflex origin, vagally mediated, and is due in part or wholly to mediator-release in type $B$ reactions.

Bronchoconstrictor effects of deep inspirations (DI) in asthmatic patients have been reported by several authors (Herxheimer, 1946; Dubois et al, 1956; Gimeno et al, 1972; Messerli et al, 1975; Roncoroni et al, 1975; Fish et al, 1977) and related to the bronchial hyperreactivity described in asthma (Simonsson $e t$ al, 1967). The prevalence of such a reaction remains ill-defined. We have previously observed (Gayrard et al, 1975), however, that brief bronchoconstriction is induced by DI in most asthmatic patients though in some, DI results in sustained effects.

The purposes of the present study were $(a)$ to define the two types of response to DI; $(b)$ to investigate the influence of repeating DI on these responses, since maximal ventilatory manoeuvres are required during routine measurement of pulmonary function and are repeated at variable intervals, especially during bronchial provocation

*Supported in part by the Institut National de la Santé et de la Recherche Médicale (INSERM). tests; and (c) to gain some insight into the different mechanisms affected by observing the effects of $\delta$ various pharmacological agents on the response to repeated DI.

\section{Methods}

Thoracic gas volume (Vtg) and specific airway resistance (sRaw) were measured in a pressure $\tilde{O}$ body plethysmograph according to the technique $\mathbb{\omega}^{N}$ of Dubois et al (1956). The airflow was measured 9 with a Fleisch No 2 pneumotachograph and $a_{0}$

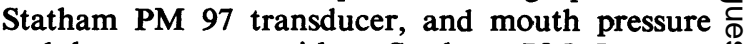
and box pressure with a Statham PM 5 and a $\stackrel{\oplus}{+}$ Statham PM 97 transducer respectively. The signals were amplified by a multichanel Recorder (DR 8, Electronics for Medicine, White Plains, NY). SRaw was measured during panting at a $\stackrel{\mathbb{Q}}{\mathscr{Q}}$ volume close to functional residual capacity (FRC). Each measurement was followed by a determination of Vtg. Inspiratory capacity-that 
is, the maximum volume of air that can be inhaled from FRC-was measured with a 9 litre spirometer (Warren E Collins, Inc, Boston, Mass).

The subject was seated in the plethysmograph and connected via the mouthpiece to the spirometer. Each DI manoeuvre (two inspiratory capacities) was repeated four times, after two randomised protocols, on different days:

(A) each DI manoeuvre was repeated with no interval except for the time needed for the sRaw measurement, about 1 minute, and

(B) repeated DI manoeuvres were separated by sRaw measurement, a two-minute rest, and another sRaw measurement.

During additional sessions one or other of the following agents was administered by inhalation before the DI manoeuvres: a beta-adrenergic stimulant (BAS, salbutamol aerosol, 0.2-0.4 mg); an anticholinergic agent (AC, ipratropium bromide aerosol: Sch $1000 \quad 0.4-2 \mathrm{mg}$ ) (Engelhardt and Klupp, 1975); or disodium cromoglycate (DSCG $100 \mathrm{mg}$ ), a drug known to prevent mediator release from mast-cells. The aerosols were taken during a submaximal inspiration from FRC, and followed by a four-second breath-hold. DSCG powder was administered by a compressed-air nebuliser (Aerosolan Gauthier) and inhaled by the subject breathing through a two-way valve until completion. The subjects were then asked to rest five minutes after BAS, 15 minutes after AC, and 20 minutes after DSCG.

Although rather high doses of AC were administered, we observed few side effects except inhibition of the salivary secretion.

Inhibition of the bronchoconstrictor effect of DI was expressed as a percentage, according to the formula

$$
\frac{a-b}{a} \times 100
$$

where (a): control increase in sRaw after DI (smallest change observed) and (b): increase in sRaw after DI with prior administration of a pharmacological agent.

\section{Patients}

Thirty-four adults (19 men, 15 women) with a history of asthma volunteered for the study. Their mean age was 35.4 years (range 16-57). Although their asthma was in remission, a variable degree of airway obstruction was noted in several subjects and was shown to be largely reversible with bronchodilator treatment in each case. The patients did not take any medication for at least 18 hours before examination.

\section{Results}

\section{TYPES OF RESPONSES}

We selected from the 34 subjects 10 responders (table 1) who showed a consistent increase in sRaw (larger than $40 \%$ of the initial value) after DI when examined on different occasions. Of the 24 remaining subjects, the responses were weaker in 13 and insignificant in 11. Even in the responders variations were observed within subjects, and for a given subject from day to day, as in patient 3 (table 2). These could not be related to changes in initial sRaw. The various characteristics of the responses to DI-delay of onset and magnitude and influence of repeated DI-are presented in table 2. Two types of responses were identified, considering the delay of peak responses

Table 1 Responders who showed a consistent increase in sRaw (larger than $40 \%$ of the initial value) after $D I$

\begin{tabular}{|c|c|c|c|c|c|c|}
\hline Patient & Age (years) & $\operatorname{Sex}$ & $\begin{array}{l}\text { Duration of asthma } \\
\text { (years) }\end{array}$ & Severity grade* & Allergic skin tests $\dagger$ & $\begin{array}{l}\text { Initial sRaw } \ddagger \text { range } \\
\left(\mathrm{cmH}_{2} \mathrm{OL} \mathrm{L}^{-1} s \times V t g\right)\end{array}$ \\
\hline $\begin{array}{r}1 \\
2 \\
3 \\
4 \\
5 \\
6 \\
7 \\
8 \\
9 \\
10\end{array}$ & $\begin{array}{l}25 \\
52 \\
28 \\
44 \\
40 \\
33 \\
39 \\
42 \\
18 \\
23\end{array}$ & $\begin{array}{l}\mathbf{F} \\
\mathbf{F} \\
\mathbf{F} \\
\mathbf{F} \\
\mathbf{M} \\
\mathbf{F} \\
\mathbf{M} \\
\mathbf{M} \\
\mathbf{M} \\
\mathbf{M}\end{array}$ & $\begin{array}{r}20 \\
10 \\
5 \\
10 \\
17 \\
11 \\
14 \\
20 \\
10 \\
12\end{array}$ & $\begin{array}{l}3 \\
2 \\
2 \\
2 \\
3 \\
2 \\
2 \\
3 \\
2 \\
2\end{array}$ & $\begin{array}{l}++ \\
++ \\
0 \\
0 \\
++ \\
++ \\
+ \\
+ \\
+ \\
++\end{array}$ & $\begin{array}{r}18 \cdot 0-30 \cdot 0 \\
11 \cdot 0-14 \cdot 0 \\
11 \cdot 0-37 \cdot 0 \\
8 \cdot 5-15 \cdot 0 \\
7 \cdot 0-8 \cdot 5 \\
6 \cdot 5-9 \cdot 0 \\
9 \cdot 0-14 \cdot 0 \\
11 \cdot 0-12 \cdot 0 \\
5 \cdot 0-7 \cdot 0 \\
11 \cdot 0-18 \cdot 0\end{array}$ \\
\hline
\end{tabular}

*Severity of the disease as determined by the frequency of attacks of asthma ( $3=$ one a day, $2=0$ one a week, $1=0$ one a month).

tSkin tests reaction: absent $(0)$, present to one $(+)$ or more $(++)$ allergens.

$\ddagger$ Lowest and highest initial specific airway resistance (sRaw) observed over the period of the study. Normal values $\leqslant 6 \cdot 5 \mathrm{cmH} \mathrm{H}_{2} \mathrm{O} L^{-1} s \times V t g$ ( $=0.65 \mathrm{kPas}$ ).

Vtg $=$ Thoracic gas volume. 
Table 2 Increase in sRaw after deep inspiration (DI)

\begin{tabular}{|c|c|c|c|c|c|c|c|c|}
\hline \multirow[t]{2}{*}{ Patient } & \multirow[t]{2}{*}{$\begin{array}{l}\text { Maximal } \\
\text { effect* }\end{array}$} & \multirow[t]{2}{*}{$\begin{array}{l}\text { Intensity }(\% \text { change } \\
\text { in sRaw range }) \dagger\end{array}$} & \multirow[t]{2}{*}{$\begin{array}{l}\text { Increase in FRC } \\
\text { (largest \% change) }\end{array}$} & \multicolumn{2}{|c|}{$\begin{array}{l}\text { Bronchoconstrictor effects of } \\
\text { repeated DI }\end{array}$} & \multicolumn{3}{|c|}{ Inhibition ( $\%$ of control) $\S$} \\
\hline & & & & With interval & Without interval & $A C$ & $D S C G$ & $B A S$ \\
\hline 1 & Imm & \} $\begin{array}{l}+50 \% \\
+\quad 77 \%\end{array}$ & $+15 \%$ & Reproducible & Decreasing & $100 \%$ & $0 \%$ & $100 \%$ \\
\hline 2 & Imm & $\left\{\begin{array}{l}+40 \% \\
+114 \%\end{array}\right.$ & $+13 \%$ & Reproducible & Decreasing & $100 \%$ & $0 \%$ & $100 \%$ \\
\hline 3 & Imm & $\left\{\begin{array}{l}+209 \% \\
+809 \%\end{array}\right.$ & $+52 \%$ & Decreasing & Reproducible & $0 \%$ & $0 \%$ & $100 \%$ \\
\hline 4 & Imm & $\left\{\begin{array}{l}+290 \% \\
+300 \%\end{array}\right.$ & $+52 \%$ & Reproducible & Decreasing & $65 \%$ & - & $66 \%$ \\
\hline 5 & Imm & $\begin{array}{l}+111 \% \\
+228 \%\end{array}$ & $+20 \%$ & Reproducible & Plateau & $81 \%$ & - & $100 \%$ \\
\hline 6 & Imm & $\left\{\begin{array}{l}+61 \% \\
+135 \%\end{array}\right.$ & $+6 \%$ & Reproducible & Plateau & $78 \%$ & - & $100 \%$ \\
\hline 7 & Imm & $+122 \%$ & $+25 \%$ & Plateau & Plateau & $0 \%$ & $0 \%$ & $100 \%$ \\
\hline 8 & Imm & $\left\{\begin{array}{l}+61 \% \\
+135 \%\end{array}\right.$ & $+6 \%$ & Reproducible & Reproducible & $90 \%$ & - & $100 \%$ \\
\hline 9 & Del & \}$+950 \%$ & $+56 \%$ & Increasing & Increasing & $81 \%$ & $96 \%$ & $100 \%$ \\
\hline 10 & Del & $\left\{\begin{array}{l}+172 \% \\
+284 \%\end{array}\right.$ & $+52 \%$ & Increasing & Delayed & $0 \%$ & $100 \%$ & $100 \%$ \\
\hline
\end{tabular}

* Maximal increase in sRaw after DI: Imm=immediate, Del=delayed, reached after few minutes.

†Lowest and highest observed percentage change in sRaw.

IInterval: three min between each DI. Reproducible, etc ... . see text.

\&AC $=$ after anticholinergic $;$ DSCG $=$ after disodium cromoglycate $; B A S=$ after beta-adrenergic stimulant.

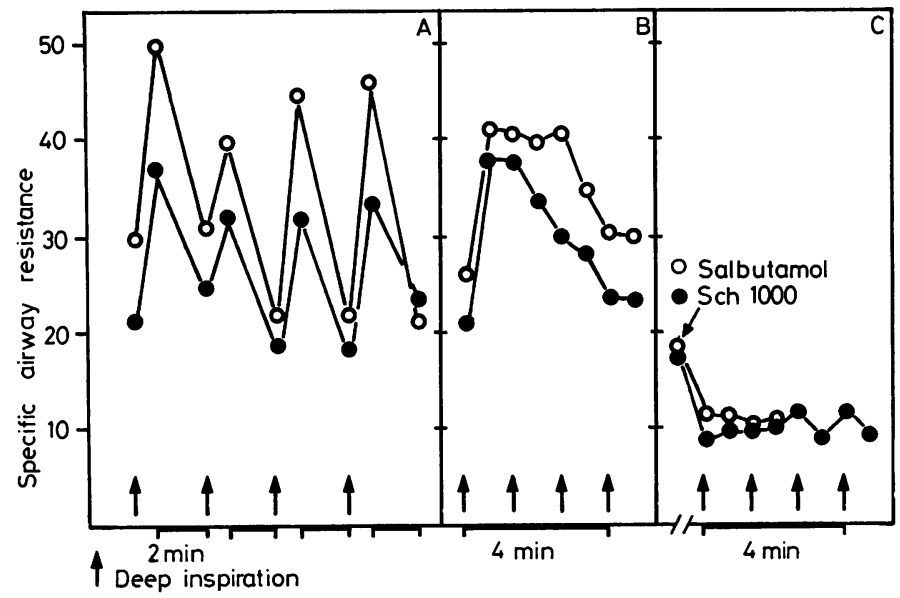

Fig 1 Asthmatic subject 1. Effects of deep inspiration $(D I)$, repeated with $(A)$ or without $(B)$ time interval on specific resistance $\left(\mathrm{sRaw}=\mathrm{CmH}_{2} \mathrm{O}\right.$ $L^{-1}$ s or $0.1 \mathrm{KPa} \mathrm{L}^{-1} s \times V t g$ ). Panels $A$ and $B$ show duplicated responses. Panel C: responses to DI with prior administration of beta-adrenergic stimulant (salbutamol, $0 \cdot 2 \mathrm{mg}$ ) and an anticholinergic agent (Sch 1000 , $0.6 \mathrm{mg}$ ).

after DI: immediate versus late, described respectively as type $\mathrm{A}$ and type $\mathrm{B}$ responses.

Immediate peak response (type A)-In eight subjects ( 1 to 8$)$ DI produced an immediate maximal rise in sRaw. The magnitude of the increase in sRaw ranged from $+40 \%$ to $+809 \%$ of the initial value (table 2). Some subjects complained of chest tightness and also wheezed. An increase in FRC paralleled the rise in sRaw (table 2). Both increases were short-lived. SRaw declined toward its baseline value within three minutes in all cases, as in fig 1a.

Delayed peak response (type B)—In two subjects
$(9,10)$ sRaw gradually increased at the first and $N$ third minute after DI. This reaction lasted for at $\mathrm{N}$ least 20 minutes.

\section{EFFECT OF REPEATED DI}

In type A the response to repeated DI with time $\stackrel{0}{\rightarrow}$ intervals showed good reproducibility (fig 1a). In 0 one subject (patient 3 , fig $2 a$ ), however, the responses decreased progressively with repeated DI. In another subject (patient 7, fig 3a) after the rise in sRaw induced by the first DI, sRaw did not return to the initial value, and there was a decline in the subsequent responses to DI, resulting in an 


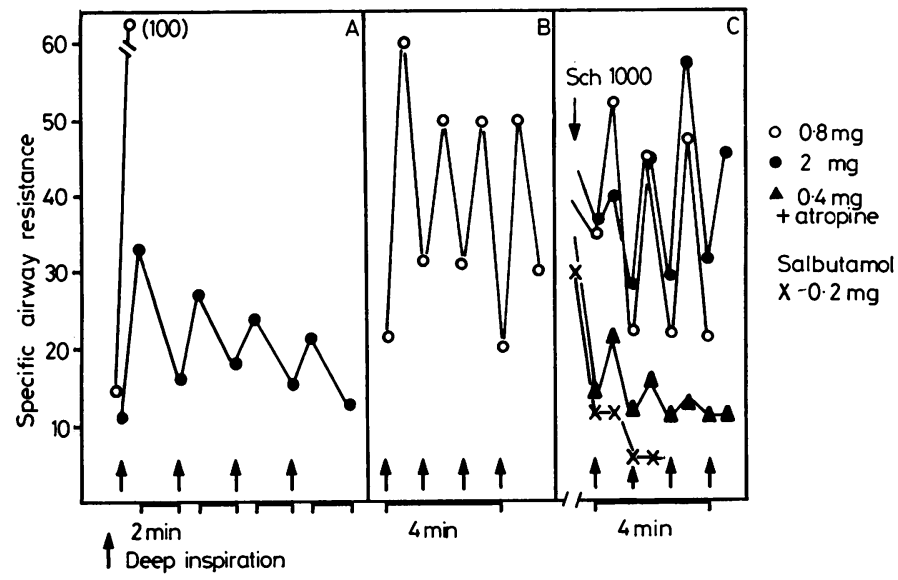

Fig 2 Asthmatic subject 3. As in fig 1. In addition, panel $A$ shows one response to a single DI (open circles) during another session, Panel $C$ shows responses to DI with prior administration of a beta-adrenergic stimulant (salbutamol) and an anticholinergic agent (Sch 1000) alone (circles) and with atropine intravenously, $0.5 \mathrm{mg}$ (triangles).

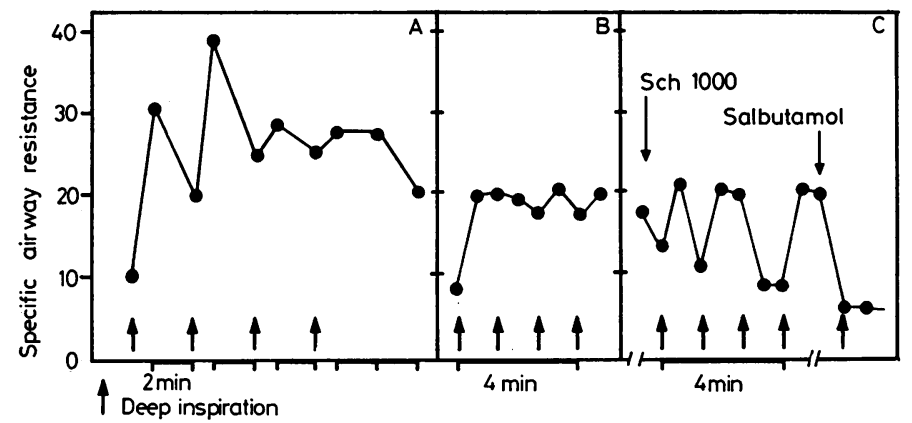

Fig 3 Asthmatic subject 7. As in fig 1: Panel $C$ shows responses to $D I$ with prior administration of an anticholinergic agent (Sch 1000, $1 \mathrm{mg}$ ), and a beta-adrenergic stimulant (salbutamol, $0.2 \mathrm{mg}$ ) successively.

increased and steady level of sRaw, or "plateau effect." When repeated with no time interval DI induced reproducible responses in only two of the eight subjects. In the remaining six patients after the initial rise in sRaw subsequent DI produced a plateau response as in fig $3 \mathrm{~b}$ (three subjects) or a decline in sRaw to baseline values, as in fig $2 \mathrm{~b}$ (three subjects).

In the two subjects with type $B$ reactions after the persistent rise in sRaw induced by the initial DI, subsequent DI produced further increase in sRaw (fig 4a) and a simultaneous increase in FRC (table 2). The repetition of DI without a time interval induced a faster rise in sRaw in subject 9. In contrast repeated DI without a time interval seemed to postpone the onset of increase in sRaw in subject 10 (fig $4 b$ ).

ADMINISTRATION OF PHARMACOLOGICAL AGENTS Inhalation of a beta-adrenergic stimulant (BAS) completely prevented the responses to DI in nine of the 10 cases (table 2, figs $1 c, 2 c, 3 c$ ). In contrast the effect of DI was reduced by subsequent administration of BAS (figs 3c, $4 b$ ) in all cases.

The anticholinergic agent ipratropium (AC, Sch 1000$)$ largely prevented $(65 \%$ to $100 \%)$ the reactions to DI in six of the eight subjects with type A response. Both BAS and AC decreased the baseline sRaw (figs 1c, 2c, 3c, 4c) and FRC. In subject 7 (fig 3c) AC decreased the baseline sRaw, with little influence on the response to DI itself. Although large amounts of AC did not influence the peak response to DI in subject 3 (fig 2), inhibition was obtained by an additional intravenous injection of atropine sulphate $(0.5 \mathrm{mg})$. In type $B$ reactions the responses to DI were inhibited by AC in subject 9 (table 2) but not in subject 10 (table 2 , fig $4 \mathrm{c}$ ).

When administered to four of the eight subjects with type A reactions DSCG failed to show any protective effect. Conversely, pretreatment with DSCG inhibited the response to DI in the two subjects with type $B$ reactions (table 2). In subject 10 DSCG decreased the baseline value for 


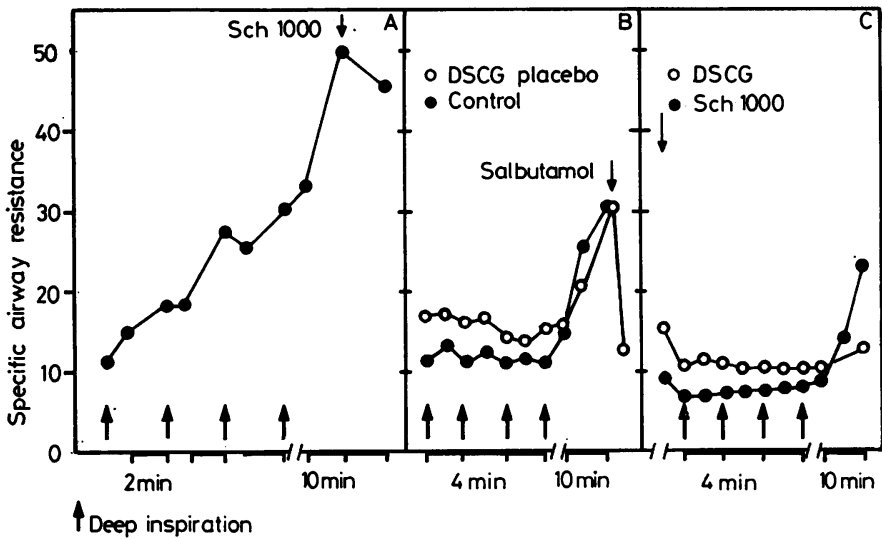

Fig 4 Asthmatic subject 10. As in fig 1 . In addition, panel $A$ shows effect of an anticholinergic agent (Sch 1000, 0.5 mg) on increased sRaw and panel $B$ shows responses to DI with prior administration of disodium cromoglycate (DSCG)placebo as well as effect of $a$ beta-adrenergic stimulant (salbutamol $0.2 \mathrm{mg}$ ) on increased sRaw. Panel $C$ shows responses to $D I$ with prior administration of an anticholinergic agent (Sch 1000, 1mg) and DSCG (100 mg).
sRaw (fig 4c), and this effect was reproduced several times.

CORRELATIONS BETWEEN BRONCHIAL RESPONSES TO DI AND THE CLINICAL AND FUNCTIONAL

CHARACTERISTICS OF THE SUBJECTS

There was no significant correlation $(P>0.1)$ between the increase in sRaw after DI and initial baseline values (tables 1,2 ) in subjects with type $A$ response. No correlation was found between the degree of responsiveness to DI and the physical or clinical characteristics of the patients (table 1 ). All responders suffered from rather severe asthma, however, and the two subjects with type B reactions were younger and had a history of exercise-induced asthma.

\section{Discussion}

Bronchoconstrictor response to DI appears as a highly variable feature in asthmatic patients and its frequency of occurrence in our group (23/34) has little statistical meaning. The variation of response observed between subjects and within subjects from day to day introduce an unpredictable influence on the respiratory manoeuvres performed during respiratory function testing in asthmatic patients.

The reactions of our subjects with type B responses resemble those described by Gimeno et al (1972) and Messerli et al (1975). We find the occurrence of such reactions to be far less frequent than that of type $\mathrm{A}$. This can be approximated to $1 \%$ of an overall adult asthmatic population in Gimeno's publication.

Repeated DI produced no cumulative effect in patients with type A reactions. It is interesting to compare this finding with the observation of Fish et al (1977) that after methacholine-induced bronchoconstriction DI was followed by small and variable changes in airway conductance, in contrast to the fall produced by DI in the control state. Although these data suggest a limited influence of repeated DI, we have previously shown (Orehek et al, 1975a) that the overall effect results in a potentiation of the bronchial response during provocation tests. Moreover, repeating DI, and particularly when this was done without a time interval, produced in some patients a reduction in the magnitude of the response. In consequence, the time interval between repeated respiratory manoeuvres will unpredictably modify the influence of such manoeuvres on respiratory function testing.

In the few cases with type $B$ reactions the cumulative responses to repeated DI could lead to false conclusions during provocation tests: increasing responses may be due to the manoeuvres rather than to the administered bronchoconstrictor substance.

Our study confirms previous work (Simonsson et al, 1967; Gayrard et al, 1975) showing that the increase in sRaw after DI is due to bronchoconstriction. This response exhibited the clinical and functional features of an attack of asthma. Moreover, the response to DI could be inhibited by bronchodilator agents, thus showing its muscular origin; the inhibitory influence of BAS rules out other possible causes of acute bronchial obstruction after DI, such as sudden glandular secretion, tissue oedema, or a decrease in lung elastic recoil and in airway calibre resulting from sudden inflation (Finucane and Colebatch, 1969).

Type A responses to DI with an immediate maximum were attributed to a vagal reflex. Such a reflex could originate from indirect stimulation, 
by bronchial stretching during DI of the irritant receptors (Mills et al, 1975), possibly "sensitised" in asthmatic subjects (Simonsson et al, 1967). This hypothesis was supported by the inhibitory effects of an anticholinergic agent already reported (Gayrard et al, 1975). Increasing the frequency of the stimulus (deep inspiration) modified in some cases the pattern of responses, for no obvious reason. After the bronchoconstrictor effect of the initial DI, the observed gradual decline to baseline value elicited by further DI in some instances suggests that subsequent stimuli might fall within a refractory period. A limited inhibitory effect of $\mathrm{AC}$ indicates that the drug might block increased vagal tone, but not a reflex bronchoconstrictor surge of vagal discharge. This effect was attributed to the necessary limitation of drug activity in man (Widdicombe, 1974), although the dose of AC inhaled in our experiment can be considered as maximal (Engelhardt and Klupp, 1975). Limited deposition of particles within the bronchial tree is unlikely to account for a lack of activity of the anticholinergic agent, since, under the same conditions, we observed that the BAS was active in all of the subjects tested. Since, however, an additional anticholinergic agent (atropine sulphate), given intravenously, inhibited the bronchial response to DI in subject 3 in whom AC aerosol was ineffective, it appears that the inhaled drug reached only a portion of the muscarinic receptor sites.

In contrast to the specific activity of AC (competitive antagonist), BAS, by inducing smooth muscle relaxation, prevents general changes in lung mechanics from any contracting stimulus or agent, and gives no such information.

Type $\mathbf{B}$ responses to DI, characterised by a late maximum, suggest the possible release of a mediator agent. This is consistent with the prevention of such responses by DSCG observed in this study, and reported by Messerli et al (1975).

Cholinergic pathways are also probably affected in type $\mathrm{B}$ responses that were reduced by $\mathrm{AC}$ in one of the two subjects. Different mechanisms, however, may account for the protective effect of AC: firstly, a decrease in vagal tone will alter the bronchial reactivity to various stimuli (Widdicombe, 1974), and, secondly, an inhibitory effect by AC towards mediators (Austen and Orange, 1975; Orehek et al, 1975b). Similarly, a beta-adrenergic agonist may inhibit mediator release (Austen and Orange, 1975). Thus BAS provides another mechanism of inhibition of the type $B$ responses to DI.

In subject 10 repeated DI produced no im- mediate onset of bronchoconstriction and $\mathrm{AC}$ did not prevent subsequent bronchoconstrictions. Thus this subject possibly had no vagal contribution in his response to DI. The mechanism of an immediate bronchodilator effect of DSCG in this case remains conjectural: it could be due either to a direct effect (Lavin et al, 1976) on smooth muscle, or to blockade of mediators that were being continuously released.

Knowing the response of a given asthmatic patient to maximal respiratory movements has some practical implications. In the clinical management of such patients one must avoid respiratory exercises and use appropriate protective agents.

\section{References}

Austen, K F, and Orange, R P (1975). Bronchial asthma. The possible role of the chemical mediators of immediate hypersensitivity in the pathogenesis of subacute chronic disease. American Review of Respiratory Disease, 112, 423-436.

DuBois, A B, Botelho, S Y, and Comroe, J M (1956). A new method for measuring airway resistance in man using a body plenthysmograph. Values in normal subjects and in patients with respiratory disease. Journal of Clinical Investigation, 35, 327333.

Engelhardt, A, and Klupp, H (1975). The pharmacology and toxicology of a new tropane alkaloid derivative. Postgraduate Medical Journal, 51 (suppl 7), 82-85.

Finucane, K E, and Colebatch, J H (1969). Elastic behaviour of the lung in patients with airway obstruction. Journal of Applied Physiology, 26, 330-338.

Fish, J E, Peterman, V I, and Cugell, D W (1977). Effect of deep inspiration on airway conductance in subjects with allergic rhinitis and allergic asthma. Journal of Allergy and Clinical Immunology, 60, 41-46.

Gayrard, P, Orehek, J, Grimaud, $\mathrm{Ch}$, and Charpin, J (1975). Bronchoconstrictor effects of a deep inspiration in patients with asthma. American Review of Respiratory Disease, 111, 433-439.

Gimeno, F, Berg, W C, Sluiter, M J, and Tammeling, G J 1972). Spirometry-induced bronchial obstruction. American Review of Respiratory Disease, $105,68-74$.

Herxheimer, H (1946). Hyperventilation asthma. Lancet, 1, 83-87.

Lavin, N, Rachelefsky, G, and Kaplan, S (1976). An action of disodium cromoglycate: inhibition of cyclic 3', 5'-AMP phosphodiesterase. Journal of Allergy and Clinical Immunology, 57, 80-88.

Messerli, Ch, Kyd, K, and Scherrer, M (1975). Cromolyn and deep inspiration-induced bronchoconstriction. Pneumology, 153, 73-80. 
Mills, J A, Sellick, H, and Widdicombe, J G (1969). Activity of lung irritant receptors in pulmonary microembolism, anaphylaxis and drug-induced bronchoconstrictions. Journal of Physiology (London), 203, 337-357.

Orehek, J, Gayrard, P, Grimaud, Ch, and Charpin, $\mathrm{J}$ (1975a). Effect of maximal respiratory manoeuvres on bronchial sensitivity of asthmatic patients as compared to normal people. British Medical Journal, 1, 123-125.

Orehek, J, Gayrard, P, Grimaud, Ch, and Charpin, J (1975b). Bronchoconstriction provoquée par l'inhalation d'allergène dans l'asthme. Effet antagoniste d'un anticholinergique de synthèse. Bulletin de Physio-pathologie Respiratoire, 11, 193201.
Roncoroni, A, Goldman, E, Puy, R, and Mancino, $M \stackrel{\overrightarrow{\vec{S}}}{\vec{P}}$ (1975). Bronchoconstriction induced by repeated forced vital capacity manoeuvres. Acta Allergologica, 30, 375-389.

Simonsson, B, Jacobs, F, and Nadel, J (1967). Role of $\overrightarrow{\widetilde{D}}$ autonomic nervous system and the cough reflex in $ᄋ$ the increased responsiveness of airways in patients with obstructive airway disease. Journal of Clinical $\rightarrow$ Investigation, 46, 1812-1818.

Widdicombe, J G (1974). Pathophysiology of lung $\overrightarrow{\vec{\omega}}$ reflexes. Bulletin de Physio-pathologie Respiratoire, $10,65-69$.

Requests for reprints to: Dr P Gayrard, Clinique de $\stackrel{\omega}{\oplus}$ Pneumo-Phtisiologie et Allergologie Hôpital St i Marguerite, BP 29-13274, Marseille Cedex 2.

\section{The Dr H M (Bill) Foreman Memorial Fund}

The trustees of the above fund invite applications from medical practitioners for fellowships in the study of respiratory disease. Grants for travel to, and support for clinical research in, countries other than the applicants own are available to a sum of $£ 800$.

Intending applicants should write for further details to Dr B H Davies, Sully Hospital, Sully, South Glamorgan, UK. 